\title{
Does RAS-based Instruction Make a Difference? An Investigation of the Effect on Vocabulary Learning
}

\author{
Mehdi Javid \\ M.A graduate in TEFL \\ PO Box: 17156-64691, Tehran, Iran \\ Tel: 98-935-305-9840_E-mail: mjavid57@yahoo.com
}

Received: July 12, 2013 Accepted: August 13, 2013 Published: August 13, 2013

doi:10.5296/ijele.v1i3.4116 URL: http://dx.doi.org/10.5296/ijele.v1i3.4116

\begin{abstract}
This study was conducted to combine the scientific findings of the human brain, especially Reticular Activating System (RAS), or attention center in the brain, to an explicit approach of vocabulary instruction. The purpose of the present study is to examine the effects of a RAS-based instruction (RASBI) on learning vocabulary of EFL elementary students and then to compare it with translation based instruction (TBI). Sixty male participants were chosen from among 92 elementary EFL learners whose levels of proficiency were determined by Michigan test. The learners under study were randomly divided into two groups: the first group, consisting of 30 students, received a RAS-based vocabulary instruction (RASBVI). The other group, consisting of 30 students, received a translation based vocabulary instruction. Data analysis and statistical calculations of pre-tests and post-tests indicated that those participants who received RAS-based vocabulary instruction outperformed their counterparts in the second group that received translation based vocabulary instruction.
\end{abstract}

Keywords: Reticular activating system, RAS-based instruction, Translation based instruction, EFL, Vocabulary teaching 


\section{Introduction}

Although it is valuable for teachers to be familiar with neuroscientific research and pass relevant findings along to education stakeholders, it is crucial that educators use classroom strategies that reflect what neuroscientists know about the brain and learning (Willis, 2007). Andrew Davis in his article 'The Credentials of Brain-Based Learning' points out that it is important to ask how far brain science can contribute to our understanding of learning (2005), and for me, as an EFL teacher, it is important to ask how far brain science, especially findings on Reticular Activating System (RAS), can help my students to learn English words more effectively.

I wonder whether we can utilize these findings to get positive effects in, let say, teaching vocabulary. In fact, the purpose of this study is to examine the effects of a 'RAS-based' vocabulary instruction on learning vocabulary among elementary students and then to compare it with a traditional instruction.

This study seeks answers to the following questions: Do scores of the participants receiving a RASBI differs significantly in the pre-test and post-test? Do scores of the participants who receive TBI differ significantly in the pre-test and post-test? Is there any significant difference between the scores of the participants receiving a RASBI and that of those who receive TBI?

In order to investigate the above-mentioned research questions empirically, the following null hypotheses are stated:

HO (1): There is no statistically significant difference between the pre-test and post-test scores of the participants receiving a RASBI.

HO (2): There is no statistically significant difference between the pre-test and post-test scores of the participants receiving a TBI.

HO (3): There is no statistically significant difference between the scores of the participants who receive a RASBI and that of those who receives a TBI.

\section{Review of Literature}

After World War II, Moruzzi and Magoun's (1949) observations gave birth to an amazing discovery in brain science: Reticular Activating System (RAS). Physiologically, RAS is connected at its base to the spinal cord where it receives information projected directly from the ascending sensory tracts (Kalat, 1995). Numerous studies have shown that it plays a significant role in determining whether a person can learn and remember things well or not, on whether or not a person is impulsive or self-controlled, on whether or not a person has high or low motor activity levels, and on whether or not a person is highly motivated or bored easily. In fact, it is the attention center in the brain and the key to "turning on our students' brain," and also seems to be the center of motivation and concentration (Jones, 2003; Koehler \& Wijdicks, 2008; Larner, 2008; Moruzzi \& Magoun, 1949; Newman, 1995; Richards, 2004; Rost, 2001; Steriade, 1996; White, 2007; Willis, 2007; Zeman, 2001). 
A more common name for RAS is the Attention Maker because it has two specific jobs: it "makes" or "breaks" attention (Bowman \& Meier, 2005). When functioning normally, it provides the neural connections that are needed for the processing and learning of information, and the ability to 'pay attention' to the correct task. According to Harvard Medical School, current research strongly suggests that Attention Deficit/Hyperactivity Disorder (ADHD) is caused in part by a deficiency of the ascending reticular activating system. To solve this problem, scientists say that an optimal amount of arousal is required to maintain attentional focus and reduce response variability (Zentall, 2005).

The optimal stimulation theory (OST) was first presented by Hebb (1955) and Leuba (1955) as a general explanation for the activity observed in all organisms. They provided evidence that the RAS needs stimulation to maintain its functioning, and that activity was the primary means to self-regulate stimulation. Since that early conceptualization researchers have presented evidence suggesting that individuals learn to produce stimulation through shifts in attention, thought/daydreaming, talking or changes in topics of conversation and in seeking social/emotional stimulation and experiences (e.g., risk-taking, exciting, illegal, or aggressive behavior; Meyer \& Zentall, 1995; Zentall, 2005).

Regardless of the way students seek additional stimulation effective performance depends on the stimulation available externally from the task and setting of the classroom. To lead students to effective performance, Zentall (2005) presents specific evidence-based practices and strategies that can be used to engage reticular activating system (or the attention) of students with ADHD. These strategies are derived from theory, with confirmatory evidence indicating that any strong stimulus has the capacity to maintain the attention of students with ADHD.

Combining these strategies which are deeply rooted in more than 50 years of theoretical and evidence-based findings to an approach of vocabulary instruction (Hunt \& Beglar, 2002), this paper attempts to present and examine a new framework for vocabulary improvement in elementary levels.

\section{Methodology}

\subsection{Participants}

The participants in this study consisted of 60 Iranian learners of English studying at university level. All of them speak Persian as their first language (L1) and study English as their university courses. The age of the students ranged from 20 to 21 years old. The participants were divided into two groups. One group served as a treatment group $(n=30)$ receiving a RASBI. The second group served as a control $(n=30)$ and received a traditional or translation-based instruction on the target words.

\subsection{Material}

Michigan English language test was used to select the participants in this study based on their language proficiency. 60 elementary students were chosen from among 92 examinees.

Ten passages which contain ten elementary words were chosen from Teamwork Police 


\section{Macrothink \\ International Journal of English Language Education \\ ISSN 2325-0887 \\ 2013, Vol. 1, No. 3}

Service which is designed for elementary students of UK and taught for both groups:

The list of ten vocabularies that each group received through both instructions is as follows:

Superintendent
Constable
Sergeant
Patrol
Detective
Crime scene
Crime prevention
Intelligence
Dog handler
Weapon

In order to test the effects of the instructions, two vocabulary tests which were adopted from the textbook, were administered in two sessions (pre and post).

\subsection{Procedure}

The design of the study was pretest-posttest nonequivalent group design, one of quasi-experimental designs, with the test scores being the dependent variable and type of instruction (RASBI, TBI or control) as the independent variable.

\subsubsection{Vocabulary Instructions}

A. RAS-based instruction (RASBI): The first group (group A, $\mathrm{n}=30$ ) were taught 10 elementary words in 2 sessions with following strategies of RAS-based instruction. In this treatment, Zentall strategies were used (see Zentall, 2005).

Example in RASBI:

(By using verbal cues, Colorful words, and bold type words)

Teacher: Read the following passage and as you read, pay very close attention and try to count how many times you see the word 'century'.

A greenhorn is someone who has no experience, who is new to a situation. In the fifteenth century, a greenhorn was a young cow or ox whose horns had not yet developed. A century or so later, a greenhorn was a soldier who had not yet had any experience in battle. By the eighteenth century, a greenhorn had the meaning it has today - a person who is new in a job.

Teacher: Now, without going back, without peeking, answer the following question. How many times did I use the word 'greenhorn'? You'll notice that you have absolutely no idea 


\section{Macrothink}

how many times I used the word greenhorn. You may have a guess, but chances are it is not correct. When you wanted to answer the first question your reticular activating system filtered out all other information and you had your attention to the word century. In fact I wanted to teach you the word 'greenhorn' and that was just a warming up with the word century. Now you can go back to count how many times you read the word 'greenhorn'.

\section{B. Translation-based instruction (TBI)}

The second group (group $\mathrm{B}, \mathrm{n}=30$ ) was taught the same 10 elementary words in 2 sessions through translation of related words into the native language of students.

Table 1. Types of treatment each group received

\begin{tabular}{cc}
\hline Group A Receiving Treatment & Group B Control group \\
\hline$(\mathrm{n}=30)$ & $(\mathrm{n}=30)$ \\
Receives RAS-based instruction & \\
Colorful words & Receives translation based instruction \\
bold type words & \\
verbal cues & \\
\hline
\end{tabular}

\subsection{Method}

In order to compare the relative effectiveness of both instructions, a series of T-Tests (paired samples) was used as the statistical instrument to find out if: 1 . The scores of the participants receiving a RASBI differ significantly in the pre-test and post-test; 2 . The scores of the participants who received a TBI differ significantly in the pre-test and post-test; and 3. There is any significant difference between the scores of the participants receiving a RASBI and that of those who received a TBI.

Statistical analyses allowed the researcher to discover the way different vocabulary instructions (RASBI and TBI) affected students' vocabulary learning.

\section{Results}

Table 2 presents the means and the standard deviations of the subjects in pre-test and post-test of RAS-based instruction. It shows that the means of post-test $(\mathrm{m}=17.6000)$ is higher that of pre-test $(\mathrm{m}=12.2667)$.

Table 2. Means and SD of RAS-based instruction in pre-test and post-test

\begin{tabular}{cccc}
\hline RAS-based instruction & N & Mean & Std. Deviation \\
\hline Pre-test & 30 & 12.2667 & 2.76908 \\
\hline Post-test & 30 & 17.6000 & 1.70395 \\
\hline
\end{tabular}


The difference between the scores of the participants in pre-test and post-test of RAS-based instruction is indicated in the figure 1 . The above line which relates to the scores of students in post-test presents a better condition than the below line which shows the scores of students in pre-test. Vertical line of the figure points to the scores and horizontal line indicates the number of students.

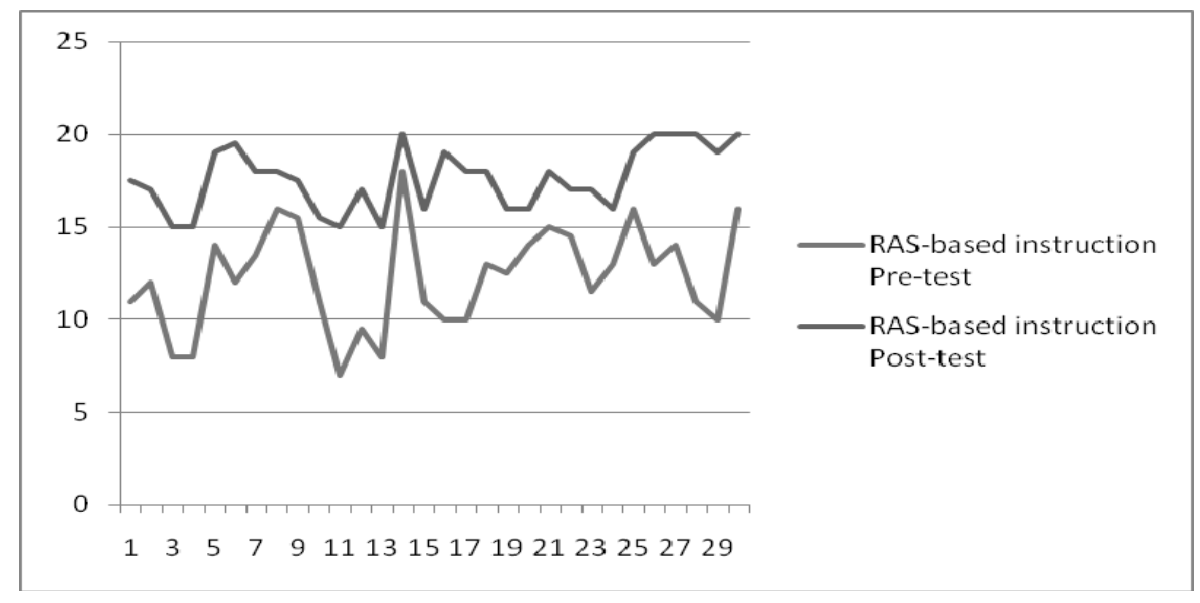

Figure 1. Pre-test and post-test of RAS-based instruction

In order to find out whether the scores of the participants receiving a RASBI differ significantly in the pre-test and post-test and to test the null hypothesis number 1 (which states that the scores of participants receiving a RASBI do not differ significantly in the pre-test and post-test.), T-Test (Paired Two Sample for Means) was run and the following results were obtained.

Table 3 indicates that t- statistical is -9.37906 and p-value is $2.77 E-10$. So H0 (1) which states there is no significant difference between the score of participants in the pre-test and post-test can be denied. Thus it can be claimed that RAS-based vocabulary instruction has significant effects on the vocabulary learning of the subjects.

Table 3. T-test: Paired two-sample for means of RASBI

\begin{tabular}{lll}
\hline & Pre-test & Post-test \\
\hline Mean & 12.26667 & 17.23333 \\
Variance & 7.667816 & 7.012644 \\
Observations & 30 & 30 \\
Pearson Correlation & 0.427375 & \\
Hypothesized Mean Difference & 0 & \\
df & 29 & \\
t Stat & -9.37906 & \\
$\mathbf{P}(\mathbf{T}<=$ t) one-tail & $1.38 \mathrm{E}-10$ & \\
t Critical one-tail & 2.462021 & \\
$\mathbf{P}(\mathbf{T}<=$ t) two-tail & $2.77 \mathrm{E}-10$ & \\
t Critical two-tail & 2.756386 & \\
\hline
\end{tabular}




\section{I Macrothink}

Table 4 presents the means and the standard deviations of the subjects in pre-test and post-test of Translation-based instruction. It shows that the means of post-test $(\mathrm{m}=13.6500)$ is higher that of pre-test $(\mathrm{m}=12.4833)$.

Table 4. Means and SD of Translation-based instruction in Pre-test and post-test

\begin{tabular}{llll}
\hline Translation -based instruction & N & Mean & Std. Deviation \\
\hline Pre-test & 30 & 12.4833 & 1.83116 \\
\hline Post-test & 30 & 13.6500 & 2.20071 \\
\hline
\end{tabular}

The difference between the scores of the participants in pre-test and post-test of Translation-based instruction is indicated in the figure 4 . The above line which relates to the scores of students in post-test presents a better condition than the below one which shows the scores of students in pre-test. Vertical line of the figure points to the scores and horizontal line indicates the number of students.

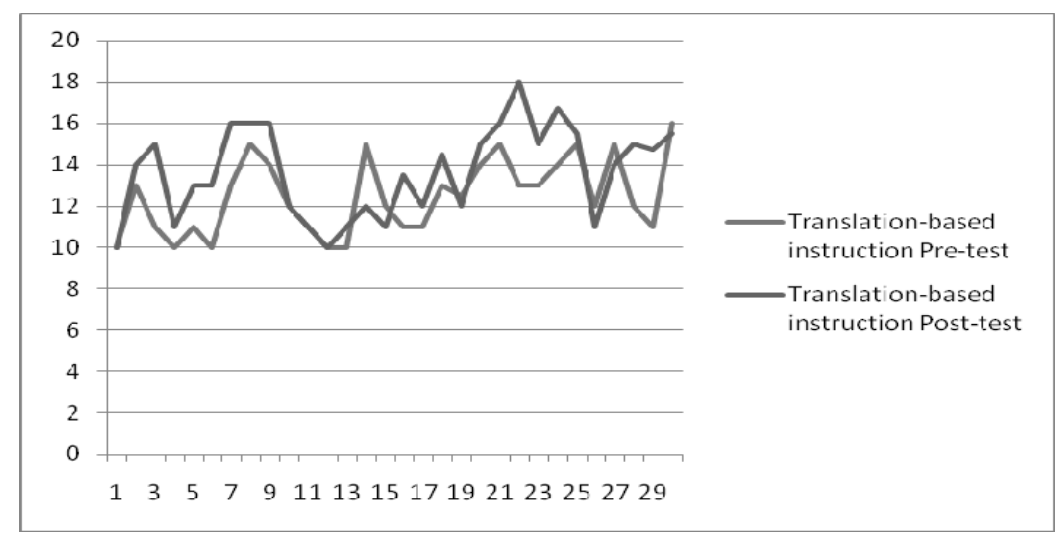

Figure 2. Pre-test and post-test of Translation-based instruction

In order to find out whether the scores of the participants receiving a TBI differ significantly in the pre-test and post-test and to test the null hypothesis number 2 (which states that the scores of participants receiving a TBI do not differ significantly in the pre-test and post-test), T-test (Paired Two Sample for Means) was run and the following results were obtained:

Table 5. T-test: Paired two-sample for means TBI

\begin{tabular}{lcc}
\hline & Pre-test & Post-test \\
\hline Mean & 12.48333 & 13.65 \\
Variance & 3.353161 & 4.843103 \\
Observations & 30 & 30 \\
Pearson Correlation & 0.635986 & \\
Hypothesized Mean Difference & 0 & \\
df & 29 & \\
t Stat & -3.64678 & \\
$\mathbf{P}(\mathbf{T}<=\mathbf{t})$ one-tail & 0.000517 &
\end{tabular}


t Critical one-tail

2.462021

$\mathbf{P}(\mathbf{T}<=\mathbf{t})$ two-tail

0.001034

t Critical two-tail

Table 5 indicates that $\mathrm{t}$ - statistical is -3.64678 and $\mathrm{p}$-value equals 0.001034 . So the formulated hypothesis that claimed there would be no significant difference between the score of participants in the pre-test and post-test can be denied. Thus it can be claimed that Translation-based vocabulary instruction has significant effects on the vocabulary learning of the subjects.

In order to understand if there is any significant difference between the scores of the participants receiving a RASBI and that of those who receive a TBI, i.e. which instruction is more effective than the other in vocabulary instruction, T-test (with Two-Sample Assuming Equal Variances) was run and the following results were obtained:

Table 6. T-test: Two-sample assuming equal variances

\begin{tabular}{lll}
\hline & Post-test $(\boldsymbol{R} \boldsymbol{A S})$ & Post-test $(\boldsymbol{T B I})$ \\
\hline Mean & 17.23333 & 13.65 \\
Variance & 7.012644 & 4.843103 \\
Observations & 30 & 30 \\
Pooled Variance & 5.927874 & \\
Hypothesized Mean Difference & 0 & \\
df & 58 & \\
t Stat & 5.700112 & \\
$\mathbf{P}(\mathbf{T}<=t)$ one-tail & $2.12 \mathrm{E}-07$ & \\
t Critical one-tail & 2.392377 & \\
$\mathbf{P}(\mathbf{T}<=t)$ two-tail & $4.23 \mathrm{E}-07$ & \\
t Critical two-tail & 2.663287 & \\
\hline
\end{tabular}

Table 6 indicates that t- statistical is 5.700112 and $\mathrm{p}$-value is $4.23 \mathrm{E}-07$. So the hypothesis that claimed there would be no significant difference between the scores of participants in the post-tests of both instructions can be denied. Thus it can be claimed that RASBI and TBI have different effects on vocabulary learning of the subjects. In other words, RASBI is more effective that TBI in vocabulary instruction.

\section{Discussion and Conclusion}

The attained outcomes of this experiment designated that the learners who received a RAS-based instruction outperformed the learners in the other group who received a translation-based vocabulary instruction.

The RAS-based model showed to be more effective than TBI in vocabulary instruction. In fact, the RAS-based model seems to have offered students a more efficient stimulus for vocabulary learning than the traditional approach. 
If teachers understand the importance of the RAS in language teaching, they probably change their instructional methods and learning activities regularly to accommodate the Attention Maker's need for stimulation. In order to really learn something (as opposed to just hearing it), the conscious mind must be fully and completely present. But in the learning stage, the RAS must engage the thinking brain. And the best way to make sure that happens is to include regular changes in both our instructional methods and the activities we use to involve learners.

The findings of this study demonstrated that using classroom strategies based on what neuroscientists know about the brain and learning can be advantageous. Indeed, it showed that using a RAS-based vocabulary instruction in elementary level, in contrast to a traditional instruction, can be led to positive effects in vocabulary learning process.

\subsection{Pedagogical Implications}

The results of the current study can infer some possible pedagogical implications practical for vocabulary instruction in EFL classrooms.

If language teachers have the perception that learning takes place when they talk and learners listen, they will probably deliver most of their information in lecture type formats. If that's the case, they run the risk of creating for learners what they have too often experienced (and what the beginning of this chapter described) - a learning environment in which the learners' conscious minds slip away even if they seem to be listening.

Students are criticized for not paying attention; they may just not pay attention to what vocabularies their teachers think are important. Novelty alerts the brain and gets it ready to pay attention. Examples of building novelty into learning new vocabularies: changes in voice, appearance, color, size, changes in seating to standing, music, dance, picture and etc. Marking key points in color results in increased recall. Teachers can also write most important vocabularies of the lesson in another color.

When teachers want their learners to pay close, conscious attention to important information, they have to catch the attention of the RAS by changing something in the environment. For example, they can engage students' Reticular Activating System through speaking in a different voice and word emphasis.

It is suggested that teachers change their instructional methods and learning activities regularly to accommodate the Attention Maker's need for stimulation during vocabulary instruction.

\subsection{Suggestions for Further Research}

The finding that RAS-based vocabulary instruction does make a difference in vocabulary learning can prompt replication of this study with other populations of different ages and proficiency levels and with different RAS-engaging techniques.

The learning strategies and training methods to keep learners' Reticular Activating Systems engaged are limited only by our own beliefs about teaching and learning. There are many 
strategies that educators can use for setting the occasion for getting optimal responses from their students in vocabulary classes.

\section{Acknowledgement}

I would like to express my gratitude to my dear colleagues and students who contributed to the conduction of this study. I am also grateful to my friends for reviewing my paper, giving invaluable comments, and helping me in the data collection sessions.

\section{References}

Bowman, S., \& Meier, D. (2005). The Ten-Minute Trainer: 150 Ways to Teach it Quick and Make it Stick! (Pfeiffer Essential Resources for Training and HR Professionals) Pfeiffer publication.

Davis, A. (2005). The Credentials of Brain-Based Learning. Journal of Philosophy of Education, 38, 21-38. http://dx.doi.org/10.1111/j.0309-8249.2004.00361.x

Dwyer, B. (2007). Training Strategies for the Twenty-First Century: Using Recent Research on Learning to Enhance Training. Innovations in Education and Teaching International, 39, 265-270. http://dx.doi.org/10.1080/13558000210161115

Hunt, A., \& Beglar, D. (2002). Current Research and Practice in Teaching Vocabulary. As cited in Methodology in Language Teaching: an Anthology of Current Practice. Cambridge University Press.

Jones, B. E. (2003). Arousal Systems. Frontiers in Bioscience, 8, 438-451. http://dx.doi.org/10.2741/1074

Kalat, J.W. (1995). Biological Psychology. Brook/Cole Publishing Company.

Koehler, P. J., \& Wijdicks, E. F. (2008). Historical Study of Coma: Looking back through Medical and Neurological Texts. Brain, 131, 877-889. http://dx.doi.org/10.1093/brain/awm332

Larner, A. J. (2008). Neuropsychological Neurology: The Neurocognitive Impairments of Neurological Disorders. Cambridge University Press. http://dx.doi.org/10.1017/CBO9780511545009

Meyer, M. J., \& Zentall, S. (1995). Observations of loud behavioral consequences: Attention Deficit Hyperactivity Disorder with and without aggression. Behavior Therapy, 36, 491-509.

Moruzzi, G., \& Magoun, H. W. (1949). Brain stem reticular formation and activation of EEG. Electroencephalography and Clinical Neurophysiology, 1, 455-473. PMid:18421835

Newman, J. (1995). Thalamic Contribution to Attention and Consciousness. Consciousness and Cognition, 4, 172-193. http://dx.doi.org/10.1006/ccog.1995.1024

Richards, J. C., \& Renandya W. A. (2002). Methodology in Language Teaching: An Anthology of Current Practice. Cambridge University Press. http://dx.doi.org/10.1017/CBO9780511667190 


\section{Macrothink}

International Journal of English Language Education

ISSN 2325-0887 2013, Vol. 1, No. 3

Richards, J. (2004). Attention. Encyclopedia of Cambridge. Retrieved from: http://jerlab.psych.sc.edu.

Rost, M. (2001). Teaching and Researching Listening. Pearson Publication.

Steriade, M. (1996). Arousal: Revisiting the Reticular Activating System. Science, 272, 225-226. http://dx.doi.org/10.1126/science.272.5259.225

White, A. (2007). The Carlbrook Brain Book. Carlbrook School Publication.

Willis, J. (2007). Neuroscience of joyful Education. Online Journal of Engaging the Whole Child, 1-4.

Willis, J. (2007). Research-Based Strategies to Ignite Student Learning and Brain Friendly Strategies for Inclusion Classrooms. Great Potentials Press.

Zeman, A. (2001). Consciousness. Brain, 124, 1263-1289. http://dx.doi.org/10.1093/brain/124.7.1263

Zentall, S. (2005). Theory- and Evidence-based Strategies for Children with Attentional Problems. Psychology in the Schools, 42, 821-836. http://dx.doi.org/10.1002/pits.20114

\section{Glossary}

ADHD: Attention Deficit/Hyperactivity Disorder

EFL: English as a Foreign Language

OST: Optimal Stimulation Theory

RAS: Reticular Activating System

RASBI: Reticular Activating System Based Instruction

RASBVI: Reticular Activating System Based Vocabulary Instruction

TBI: Translation Based Instruction

\section{Copyright Disclaimer}

Copyright reserved by the author(s).

This article is an open-access article distributed under the terms and conditions of the Creative Commons Attribution license (http://creativecommons.org/licenses/by/3.0/). 